\title{
Mecanismos municipales de control de la ocupación del espacio en la periferia de la Zona Metropolitana de la Ciudad de Toluca, Estado de México, 1983-2010
}

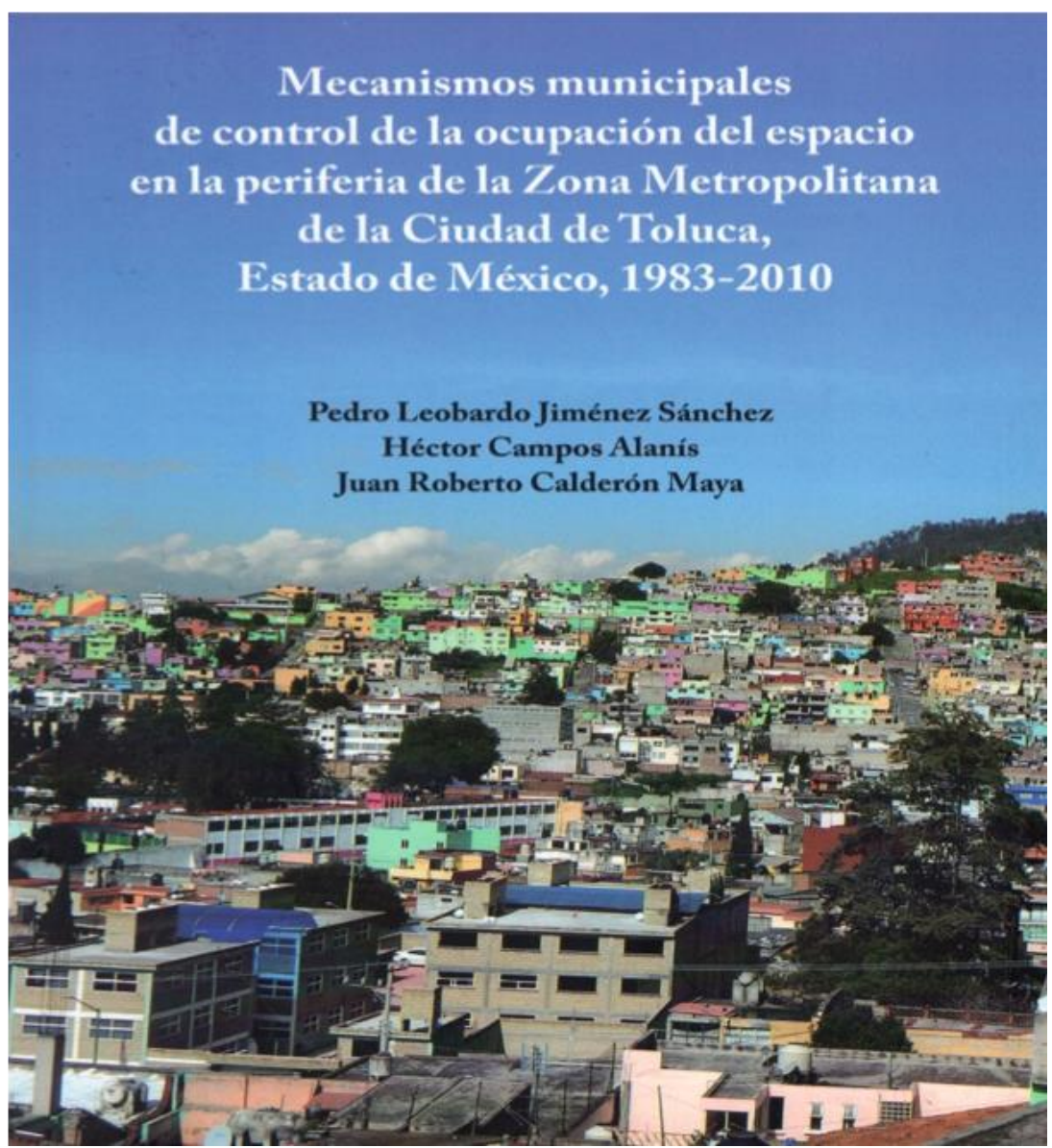

Jiménez Sánchez, Pedro Leobardo; Campos Alanís, Héctor y Calderón Maya, Juan Roberto, (2019). Mecanismos municipales de control de la ocupación del espacio en la periferia de la Zona Metropolitana de la Ciudad de Toluca, Estado de México, 1983-2010. Universidad Autónoma del Estado de México, Juan Pablos Editor. ISBN: 978-607-633-002-9 UAEMéx. ISBN: 978-607-711-5366 Juan Pablos Editor

*Universidad Autónoma del Estado de México, Facultad de Planeación Urbana y Regional, México. Correo electrónico: karenreyesaguilar@hotmail.com 
La formación académica y la orientación a la producción científica de los autores del libro Mecanismos municipales de control de la ocupación del espacio en la periferia de la Zona Metropolitana de la Ciudad de Toluca, Estado de México, 1983-2010 les ha permitido posicionarse como un referente en el campo de estudio de la planeación, el desarrollo urbano y la sustentabilidad ambiental, desde los ámbitos sociales, territoriales, económicos, político-administrativo y ambientales en México, para enfrentar los diversos problemas sociales mediante consensos con el estado y las autoridades correspondientes en materia de ocupación del espacio en zonas metropolitanas, con la finalidad de lograr el bienestar común.

Los autores del libro: Pedro Leobardo Jiménez Sánchez, Doctor en Ciencias Sociales, Miembro del Sistema Nacional de Investigadores (SNI) del Consejo Nacional de Ciencia y Tecnología (CONACyT); Héctor Campos Alanís, Maestro en Estudios Urbanos y Regionales estudiante del Doctorado en Urbanismo en la Universidad Nacional Autónoma de México (UNAM); y Juan Roberto Calderón Maya, Doctor en Urbanismo y Miembro del SNI, son profesores en la Universidad Autónoma del Estado de México; en los ámbitos nacional e internacional, han participado como ponentes y conferencistas en diversos eventos académicos-científicos, y se han desempeñado como coordinadores, compiladores y autores de publicaciones en libros y revistas científicas, asimismo, han realizado estancias académicas y de investigación en distintas universidades.

Con base en su formación académica y en sus experiencias laborales e inquietudes sobre la necesidad de atender problemas sociales, entre ellas la ocupación y la transformación del espacio y su relación con el estado respecto a su intervención con dichos procesos, desarrollaron este libro, con el objetivo de conocer y analizar los instrumentos jurídicos y los sistemas administrativos que operan los mecanismos de control municipal en el proceso de ocupación del espacio en la Zona Metropolitana de la Ciudad de Toluca (ZMCT), a fin de identificar los problemas y las causas que determinan su incapacidad de su control y ordenamiento.

En el primer apartado, exponen un marco teórico-conceptual sobre el fenómeno de la ocupación del espacio y la periferia urbana, además de la transformación del territorio a partir de procesos sociales, bajo el enfoque de la ciencia social y la geografía humana, destacando las aportaciones de Lefebvre (1991), Castells (1983), Santos (1996, 2000), Vinageras (2002) y Lezama (2002), quienes plantean que los nuevos procesos sociales han determinado una diversidad de formas de ocupación física y espacial que responde a las relaciones sociales desarrolladas en el territorio y lo configura para satisfacer las necesidades de la colectividad, sustentadas en una identidad y formas de organización, mediante la transformación de la naturaleza. 
Asimismo, consideran al territorio como un ente físico y tangible donde los actores locales desarrollan acciones y actividades que lo conforman y lo configuran; no obstante, a partir de diversas perspectivas, determinaron que la categoría de territorio ha sido sustituida por el término espacio para abordar estudios asociados con el territorio. De esta manera, definen la palabra espacio como un conjunto de sistemas de objetos y sistemas de acciones que se integran y se vinculan con la naturaleza y consolidan elementos físicos, naturales y artificiales para darle vida y funcionalidad, transformándola físicamente para llevar a cabo relaciones sociales; por lo tanto, destacan que el estudio del espacio debe situarse respecto a otras realidades, como la naturaleza y la sociedad, en donde la configuración territorial refiere al conjunto de acciones realizadas por el hombre que modifican el paisaje natural con base en la dinámica social.

Sobre la ocupación del espacio, identifican dos mecanismos para ocupar el espacio: legal e ilegal, los cuales están determinados por las relaciones sociales que se desarrollan en él; el mecanismo legal se sustenta en acciones reguladas por el estado,mientras que el ilegal corresponde a la construcción sobre terrenos no calificados ni programados para este fin. En este sentido, la expansión física de las ciudades, en las últimas décadas, ha sido desproporcionada, en especial en la ocupación de la periferia, lo que genera un fenómeno negativo en los procesos territoriales, pues surge de la especulación del suelo por la falta de viviendas en comparación con el crecimiento demográfico y de los cambios introducidos en la construcción del espacio urbano moderno. No obstante, las nuevas periferias ya no se definen en relación con el centro ni como un espacio negativo marginal, sino como un espacio que tiene identidad propia basada en cualidades de movilidad y autonomía, que le dan un nuevo sentido al lugar, convirtiéndolo en un territorio complejo de entender.

Los autores proponen un modelo metodológico sobre la ocupación del espacio en la periferia para explicarla en zonas metropolitanas; consideran necesario analizar el fenómeno metropolitano, caracterizado por el desarrollo y la expansión de la mancha urbana, seguida por un proceso de ocupación de la periferia, identificando los mecanismos e instrumentos de control y vigilancia con los que operan el estado y los gobiernos locales.

El capítulo dos tiene como objetivo identificar y analizar los instrumentos y la normatividad jurídica y administrativa que facultan a los ayuntamientos para emitir los mecanismos e instrumentos administrativos de control de la ocupación del espacio urbano. Para los autores, el estado desempeña un papel importante en el crecimiento y los cambios de una ciudad, pues su trabajo sobre la estructura urbana lleva a moldear el territorio, incidiendo en su organización y generando condiciones favorables para propiciar la regulación de la apropiación de suelo a partir de la planeación urbana; asimismo, es necesario abordar su intervención sobre las relaciones sociales, ya que, en conjunto, se convierten en instituciones que ordenan, regulan y controlan la ocupación del espacio. 
Como parte del marco jurídico municipal para la ordenación del espacio, presentan algunos antecedentes en materia de ordenamiento territorial en el Estado de México y municipios, destacando la Constitución Política de los Estados Unidos Mexicanos, la Ley General de Asentamientos Humanos y el Código Administrativo del Estado de México en materia de ordenamiento y desarrollo urbano. Por otra parte, consideran a los instrumentos como un conjunto de elementos monetarios, fiscales, sociales, administrativos y legales que promueven, regularizan y controlan diversos aspectos que incurren en el desarrollo urbano de la ciudad; con ello, identifican cinco tipos: instrumentos de actuación directa, de planeación, regulación, control y vigilancia, actuación indirecta.

Los instrumentos de control y vigilancia del espacio deben certificar la transparencia y continuación de las acciones, dar seguridad legislativa a los agentes urbanos involucrados, garantizar la colaboración imparcial de los beneficios y costos del desarrollo urbano entre las partes, así como testificar la satisfacción de las necesidades básicas de las mayorías, especialmente de aquéllas procedentes de las zonas locales. En este sentido, se identificaron los principales instrumentos de control y vigilancia de acuerdo con la legislación en materia de ordenamiento territorial: la cédula informativa de zonificación, licencia de uso de suelo, alineamiento y número oficial, licencia de construcción, inspección y aviso de terminación de obra.

Con base en el marco teórico-conceptual y jurídico-administrativo, los autores abordan el tercer capítulo con un caso de estudio específico: “Ocupación del espacio en la periferia de la Zona Metropolitana de la Ciudad de Toluca" (ZMCT), con el objetivo de analizar el proceso de ocupación del espacio en la ZMCT para identificar los asentamientos humanos irregulares desarrollados mediante las acciones de la sociedad a través de los asentamientos humanos con mayor índice de irregularidad como sistema de indicadores.

El capítulo inicia con una caracterización del fenómeno metropolitano como una condicionante del desarrollo de la expansión de la ciudad y la ocupación del espacio de la periferia; posteriormente, se delimita la periferia, para lo cual se considera la metodología establecida por instituciones oficiales y se incorpora un análisis empírico respecto a la conformación y configuración de la ZMCT, caracterizando los municipios que la integran y los procesos sociales y demográficos que se desarrollan en ellos. Finalmente, se presentan los resultados del estudio, en donde se identifica el proceso de información que explica la ocupación del espacio en la periferia, caracterizando cada uno de sus asentamientos humanos; de esta manera, se muestran las limitaciones a las cuales se enfrentan las autoridades municipales para regularizar los asentamientos humanos, convirtiéndolo en un proceso complejo. 
Así, en los municipios conurbados que conforman la ZMCT abundan asentamientos humanos irregulares, los cuales se definen por la necesidad de la población de contar con un espacio donde vivir. Entre las causas que establecen los asentamientos humanos irregulares en la periferia de la ZMCT están: invasión - como la más frecuente, venta de parcelas, ocupación de zonas de riesgo, compra ilegal, compra sin orientación, lotificaciones sin orientación, tenencia de la tierra, documento de propiedad, necesidades de suelo, usos de suelo, servicios y presupuesto. Respecto a los procesos de control de la ocupación del espacio en la periferia de la ZMCT, existen problemas y limitaciones provocados por las autoridades estatales y municipales, pues no han logrado detener los asentamientos humanos irregulares durante el proceso de emisión y operatividad de los instrumentos de control y vigilancia; así como el desinterés de la población, ejidatarios y comuneros; la falta de regularización de la tenencia de la tierra, el régimen de propiedad, los asentamientos humanos en zonas irregulares, la venta ilegal, la invasión paulatina y el uso de suelo.

En el cuarto y último capítulo del libro, se plantean las deficiencias administrativas en el control de la ocupación del espacio en la periferia de la ZMCT, con el objetivo de analizar el proceso de gestión y operatividad de los mecanismos e instrumentos de control municipal; se establecen zonas de estudio para identificar las causas que impiden controlar y ordenar el espacio urbano. De esta manera, se identifican los principales problemas de los municipios en relación con su estructura jurídico-administrativa, los inconvenientes que surgen en el proceso de emisión de los instrumentos de control y vigilancia de la ocupación del espacio y las limitaciones que se presentan al aplicar los instrumentos de control y vigilancia del espacio y que hacen ineficiente el servicio.

El análisis parte de la estructura administrativa de los ayuntamientos, la cual comprende el territorio, su población y el gobierno, pues éstos determinan su funcionalidad, facultades, actividades y emisión y operatividad de los instrumentos de control y vigilancia de ocupación del espacio. Entre los instrumentos jurídicos en los que se apoya el proceso de emisión de los instrumentos de control y vigilancia del espacio en los municipios de la ZMCT, destacan: el bando municipal que regula el desarrollo urbano, el alineamiento y el número oficial; y de materia ambiental.

Respecto a la emisión de los instrumentos de control y vigilancia en la ZMCT, depende del proceso administrativo establecido por los municipios y de las necesidades derivadas de la ocupación del espacio, por lo cual no se da eficientemente y proliferan los asentamientos humanos irregulares, respondiendo a un proceso de ocupación del espacio con base a las necesidades colectivas y a la deficiencia de los gobiernos para controlarlo. Para emitir los instrumentos de control y vigilancia, se requieren siete fases: adquisición del predio, aprovechamiento del predio, desarrollo del proyecto de aprovechamiento, restricciones de aprovechamiento y asignación de número oficial, desarrollo físico del proyecto, desarrollo de la obra y conclusión de la obra. 
Los instrumentos de control y vigilancia del espacio que operan los gobiernos municipales inciden positivamente en la ordenación de su territorio, pues otorgan certeza jurídica a la sociedad y a los agentes involucrados; no obstante, los resultados muestran los problemas que hacen ineficiente el proceso administrativo en la gestión y en la emisión de los instrumentos en los municipios que conforman la ZMCT, como la falta de espacios físicos adecuados, el trámite y la emisión de instrumentos de control y vigilancia por parte de personal especializado, los formatos utilizados, las limitaciones y necesidades de la población para atender los requerimientos, los procesos y las dificultades de inspección y supervisión de las obras y la inexistencia de área jurídica en todos los municipios.

Por lo tanto, los autores concluyen que las preeminencias del estado para ordenar, regular, controlar y vigilar el desarrollo urbano son rebasadas por las acciones de la colectividad al satisfacer sus necesidades de suelo y vivienda, pues sus instrumentos jurídicos que operan en los municipios son ineficientes y no son acordes con las necesidades sociales. La sociedad ocupa el espacio sin apego a las normas jurídicas y administrativas establecidas en los instrumentos jurídicos, de planeación y administrativos, lo cual genera los asentamientos humanos irregulares de forma ilegal, destacando la ocupación por la venta ilegal de las tierras.

Entre las principales aportaciones del libro destacan: la construcción del marco teórico sobre el proceso de ocupación del espacio en la periferia a nivel metropolitano, pues se basa en la comprensión integral de dos variables: espacio y periferia; y la realización de propuestas para tratar de mitigar los problemas identificados en los procesos de ocupación del espacio en la periferia de la ZMCT. Si bien esta obra presenta una serie de contribuciones teóricas-conceptuales, un marco jurídico-administrativo y la aplicación de un diagnóstico en un caso concreto, es necesario reconocer y atender las deficiencias identificadas en el sistema estatal y municipal, porque indican la falta de colaboración por parte de los actores sociales involucrados; los propietarios de los predios susceptibles de asentamientos humanos irregulares no tienen disposición para colaborar con leyes y reglamentos de ordenamiento territorial, debido a los trámites, el tiempo y el costo, o por la falta de conocimiento sobre los instrumentos, lo que convierte al proceso ilegal en la vía más fácil.

Por otra parte, es necesario que el estado y los municipios, con ayuda de personal especializado, gestionen nuevos mecanismos que permitan a la sociedad tener mejor acceso a los trámites para instrumentos de control y vigilancia de ocupación del espacio, los cuales detonen en la capacidad de actuación de las autoridades para resolver problemas a corto plazo, a fin de acercar a la ciudadanía a la vía legal respecto a ordenamiento y desarrollo urbano. Para que los instrumentos en materia de ocupación del espacio funcionen, son de suma importancia la participación social y la eficiencia facultativa de los actores gubernamentales e institucionales. 